\title{
Tailoring Properties of Acidic Types of Natural Deep Eutectics Solvents (NADES): Enhanced Solubility of Curcuminoids from Curcuma zeodaria
}

\author{
Orchidea Rachmaniah $^{1,}{ }^{*}$, Lailatul Jumiati Fazriyah ${ }^{1}$, Nurul Hesti Seftiyani ${ }^{1}$, and $M$. Rachimoellah ${ }^{1}$ \\ ${ }^{1}$ Department of Chemical Engineering, Faculty of Technology Industry, Institut Teknologi Sepuluh Nopember, Surabaya 60111, \\ Indonesia
}

\begin{abstract}
Recently Natural Deep Eutectic Solvents (NADES) show their potential as a promising green solvents at $21^{\text {th }}$ century for extraction of natural products. Rutin, a poorly water soluble flavonoid, was reported better solubilized in NADES than in water as well as a paclitaxel and ginkgolide B, a completely water-insoluble compound. In case of curcuminoids, phenolic compounds from powder of Curcuma Zeodaria shown better solubilized in acidic type of NADES such malic acid-sucrose-water $\left(\mathrm{MAS}-\mathrm{H}_{2} \mathrm{O}=1: 1: 11\right.$, mole ratio) and citric acid-sucrose-water (CAS- $\mathrm{H}_{2} \mathrm{O}=1: 2: 15$, mole ratio) compare to water and ethanol. Indicating that NADES, a waterbased solvent, appropriate for extracting curcuminoids. However, the inherent high viscosity of NADES hamper the process extraction. Lowering the viscosity, water content of NADES is varied, adding a certain amount of water up to $60 \%$ of water content. All the varied water content of both $\mathrm{CAS}-\mathrm{H}_{2} \mathrm{O}$ and $\mathrm{MAS}-\mathrm{H}_{2} \mathrm{O}$ were successfully extracted curcuminoids. Yielded 0.06-0.16 mg curcuminoids/g dry weight. However, $60 \%$ of water content of both $\mathrm{CAS}-\mathrm{H}_{2} \mathrm{O}$ and $\mathrm{MAS}-\mathrm{H}_{2} \mathrm{O}$ gave more or less similar value of curcuminoids to CAS $-\mathrm{H}_{2} \mathrm{O}\left(20 \%\right.$ of water) and $\mathrm{MAS}-\mathrm{H}_{2} \mathrm{O}(30 \%$ of water). Curcuminoids is more stable in $\mathrm{CAS}-\mathrm{H}_{2} \mathrm{O}$ compare to $\mathrm{MAS}-\mathrm{H}_{2} \mathrm{O}$ for $96 \mathrm{~h}$ of time duration.
\end{abstract}

\section{Introduction}

Turmeric has been found to be rich source of phenolic compounds, namely curcuminoids consisting a natural mixture of three polyphenols: curcumin (C), desmethoxycurcumin (DMC), and bisdemethoxycurcumin (BDMC). In which curcumin as the main constituent. It responsible for the biological activities of curcuma and it yellow to bright orange colour characteristic [1]. Curcumin commonly called diferuloylmethane is a fat-soluble, hydrophobic polyphenol pigment [2]; recognized for their broad spectrum of bioactivity which is safe for use in food and pharmaceuticals industries [1]. It known for its antioxidant, anti-inflammatory, anti-microbial, antiparasitic, anti-mutagenic, and anti-cancer properties $[2$, 3] which also used in the treatment of infection with human immunodeficiency virus (HIV) [1]. As an anticancer agent for various cancers such colorectal, pancreatic, breast, prostate, multiple myeloma, lung, head and neck, curcumin has been demonstrated to inhibit cancer cell survival and proliferation [4]. The chemical structure of curcumin takes responsible for its unique physicochemical and biological properties. Moreover, curcumin is highly safe consumed and well tolerated by human up to $12 \mathrm{~g} /$ day [3], prevents multidrug resistance (MDR) and chemo-resistance which are commonly occurred in cancer patients [2].

In spite all of its advantages, until now curcumin not yet been approved as a therapeutic agent. Though those multi-target bioactivities of curcumin makes it a good candidate for a chemical derived anticancer agent from plant. The explanation might be due to low solubility of curcumin in water and its poor bioavailability.

Curcumin shown a low systemic bioavailability after oral consumption, hence only a trace or even negligible amount of curcumin may found in the tissues outside the gastrointestinal tract [2]. Negligible amount of curcumin was found in blood plasma of rats after oral administration of $1 \mathrm{~g} / \mathrm{kg}$ of curcumin [3]. Practically, curcumin not soluble in water at acidic and neutral $\mathrm{pH}$, ca. $\mathrm{pH}=1-7$. In contrast with, at aqueous alkaline solution, its solubility is increased. However, at the same time curcumin degradation also takes a place $[4,5]$.

Several studies have been done to improve both of solubility and bioavailability of curcumin such: (1) adjuvants utilization, e.g. piperine [6], quercetin [7], or genistein [8], which was combined with curcumin in order to block metabolic pathways of curcumin; (2) nanoparticle technology application for triggered drug

Corresponding author: orchidea@,chem-eng.its.ac.id 
delivery system containing curcumin. However, the low solubility of curcumin in water yet the major obstacle. In addition (3) a drug delivery system based on liposomes, micelles, and phospholipid complexes were also studied.

Therefore in our preliminary study, a natural deep eutectic solvent (NADES), a recently reported green solvent [9] with wide range of solvent polarity was used. Twelve kind of different NADES were studied; determining the NADES with the highest extractability of curcuminoids from $C$. zeodaria powder. Hence, enhance the solubility of curcumin in water [10]. Though the highest extractability gives by choline chloridemalic-acid-water $\left(\mathrm{CCMA}-\mathrm{H}_{2} \mathrm{O}\right)$ at 1:1:2 mole ratio. It is found that curcumin not stable within $96 \mathrm{~h}$. Meanwhile, curcumin is also well extracted in acidic type of NADES, e.g. citric acid-sucrose-water $\left(\mathrm{CAS}-\mathrm{H}_{2} \mathrm{O}\right)$ and malic acid-sucrose-water (MAS- $\left.\mathrm{H}_{2} \mathrm{O}\right)$. Which is contrary to the fact that curcumin have low solubility at acid solution $(\mathrm{pH}=1-7)$ [5]. In addition, the inherent high viscosity of NADES reduces the mass transfer rate at the extraction process. Therefore, the effect of water content of CAS- $\mathrm{H}_{2} \mathrm{O}$ and $\mathrm{MAS}-\mathrm{H}_{2} \mathrm{O}$, by means diluting the NADES, to the extractability of curcuminoids from its plant matrix, C. zeodaria powder, was currently studied.

\section{Materials and methods}

Curcuminoids standards was purchased from TCI America. Fine powder of Curcuma zeodaria was kindly donated from Sari Herbal (Sukun, Malang, Indonesia). While individual component of NADES: sucrose, citric acid, and malic acid were purchased from Sigma Aldrich (St. Louis, MO, USA). In case of solvents such acetonitrile and acetic acid are in HPLC grade were commercially purchased form Merck.

\subsection{NADES preparation}

NADES was prepared followed a protocol by [11] with a slight modification; a freeze dry was used instead of a vacuum evaporation. Two individual compounds of NADES were precisely weighted according to its molar ratio; mixed and dissolved in water equipped with water bath $\left(70{ }^{\circ} \mathrm{C}\right)$ and stirring bar. The mixture was agitated till a clear liquid was formed. The resulted liquid called further as a NADES.

In case of water content variation, a determined amount of water, i.e. aquadest, was added to the NADES reaching the specified percentage of water content. CAS$\mathrm{H}_{2} \mathrm{O}(1: 2: 15)$ and MAS- $\mathrm{H}_{2} \mathrm{O}(1: 1: 11)$ were selected as the lowest content of water, $20 \%$ and $30 \%$ of water content respectively. Lower value of water content make the extraction process difficult, due to high viscosity of both NADES.

\subsection{Curcuminoids extraction with NADES}

Extraction was carried out by added $20 \mathrm{mg}$ of the powder of $C$. zeodaria with $5 \mathrm{~mL}$ of NADES at amber bottle with a cap, stirring $(350 \mathrm{rpm})$ at $40{ }^{\circ} \mathrm{C}$ for $24 \mathrm{~h}$.
After the extraction time was ended, $1 \mathrm{~mL}$ of each sample was collected and kept in the freeze and dark place for further analysis.

Maceration with acetone using the same plant material for $4 \mathrm{~h}$, at dark place was also conducted. Determining the initial content of curcuminoids in the raw material [12]. A 1:8 (v/w) ratio of C. zeodaria powder to acetone was applied, meaning a $37.5 \mathrm{mg}$ of powder with $300 \mathrm{~mL}$ of acetone was macerated at room temperature $\left(30^{\circ} \mathrm{C}\right)$ equipped with stirrer.

\subsection{Properties tests}

Density and viscosity of each NADES was measured in triplicates and the average value was reported. The Density was performed using pycnometer at room temperature $\left(30{ }^{\circ} \mathrm{C}\right)$ with water as a reference; whereas viscosity was determined by Ostwald viscometer.

\subsection{Curcuminoids analysis}

The extracted curcuminoids was determined by high performance liquid chromatography (HPLC) Agilent Technologies in triplicates with the following column: $3.5 \mu \mathrm{m}$ Zorbax eclipse XDB C-18 $150 \mathrm{mmx} 4.0 \mathrm{~mm}$ ID (Agilent, USA). Chromatograph was equipped with diode array detector (DAD). The detection was performed at $421 \mathrm{~nm}$. All the chromatographic measurements was performed at $35{ }^{\circ} \mathrm{C}$ and $1.0 \mathrm{~mL} / \mathrm{min}$ of flow rate. The elution was carried out with an isocratic solvent system consisted of acetonitrile:acetic acid $1 \%(50: 50, \mathrm{v} / \mathrm{v})$ with the total running time was 15 $\min$.

Prior injected to the HPLC, a ca. $200 \mathrm{mg}$ of sample was accurately weighted, diluted up to $2 \mathrm{~mL}$ with methanol; subsequently vortexed, centrifuged and filtered with $0.2 \mu \mathrm{m}$ nylon membrane syringe filter. Thus $50 \mu \mathrm{L}$ of filtrate was directly injected to HPLC for quantitatively analysis.

\section{Results and Discussion}

\subsection{Initial content of curcuminoids}

Curcuma zeodaria as a raw a material contains $1.96 \%$ dry weight of curcuminoids. It was determined by previously described maceration protocol (subsection 2.2). In case of selectivity of curcuminoids both using volatile organic solvent and NADES was presented at Table 1.

It is clearly shown that acetone is the most suitable solvent for extracting curcuminoids from its plant matrix. Therefore maceration using acetone was applied for determining the initial content of curcuminoids in the C. zeodaria powder. It is reasonable, since curcuminoids is relatively non-polar compound. "Like dissolves like", a compound will be easily dissolved in solvent with similar polarity.

In contrast, acetone is volatile and highly flammable solvent with boiling point $56{ }^{\circ} \mathrm{C}$. At high concentration, it is irritating and may depress central nervous system. Moreover, both of NADES and ethanol (EtOH) yielded 
approximately similar amount of curcuminoids. Hence, NADES is a promising solvent for curcuminoids extraction from its plant matrix. In case of lower yield of curcuminoids by EtOH, might be explained that curcuminoids are relatively medium- to non-polar compounds; therefore more suitable with acetone than EtOH. Moreover, it might be degraded considering the length of the maceration time.

Table 1. Curcuminoids yield and selectivity obtained by using different solvent including NADES.

\begin{tabular}{|c|c|c|c|c|}
\hline \multirow{2}{*}{ Solvent } & \multicolumn{3}{|c|}{$\begin{array}{c}\begin{array}{c}\text { Yield curcuminoids }\left(\mathrm{mg} / \mathrm{g}^{\mathrm{a}}\right) \\
\left(\% \text { selectivity }^{\mathrm{V}}\right)\end{array} \\
\end{array}$} & \multirow{2}{*}{$\begin{array}{c}\text { Total } \\
\text { curcuminoids } \\
\left(\mathrm{mg} / \mathrm{g} \pm \mathbf{S D} \%{ }^{\beta}\right)\end{array}$} \\
\hline & BDMC & DMC & $\mathrm{C}$ & \\
\hline Acetone $^{\lambda}$ & $2.505(13)$ & $6.693(34)$ & $10.402(53)$ & $19.600 \pm 0.35 \%$ \\
\hline Ethanol $^{\pi}$ & $0.026(17)$ & $0.034(22)$ & $0.092(61)$ & $0.152 \pm 0.43 \%$ \\
\hline $\begin{array}{l}\mathrm{CAS}-\mathrm{H}_{2} \mathrm{O}^{\kappa} \\
(1: 2: 15)\end{array}$ & $0.012(8)$ & $0.042(27)$ & $0.098(65)$ & $0.151 \pm 0.74 \%$ \\
\hline $\begin{array}{l}\text { MAS-H } \mathbf{H}_{2} \mathbf{O}^{\kappa} \\
(1: 1: 11)\end{array}$ & 0.005 (3) & $0.027(20)$ & $0.100(77)$ & $0.131 \pm 1.82 \%$ \\
\hline
\end{tabular}

${ }^{a}$ yield curcuminoid expressed as $\mathrm{mg}$ curcuminoids/g dry weight of $C$. zeodaria.

${ }^{\beta}$ deviation standard calculated from triplicate data.

${ }^{\mathrm{\gamma}}$ selectivity was calculated as percentage of total weight of extracted curcuminoids.

${ }^{\lambda}$ Maceration method was applied following [12].

${ }^{\pi}$ Maceration extraction was applied till the obtained filtrate was colourless, approximately 15 days.

${ }^{\mathrm{K}}$ Extraction was conducted for $24 \mathrm{~h}$ at $40{ }^{\circ} \mathrm{C}$ agitated with stirring bar at $350 \mathrm{rpm}$.

Selectivity of curcuminoids directly dependent to the kind of solvent (Table 1). In case of MAS- $\mathrm{H}_{2} \mathrm{O}$ (1:1:11), it gave the highest selectivity to curcumin followed with desmethoxycurcumin (DMC) and bisdemethoxycurcumin (BDMC). Whereas CAS- $\mathrm{H}_{2} \mathrm{O}$ (1:2:15) gave more or less similar selectivity of curcumin with ethanol. Despite of highest yield of curcuminoids, acetone only shown 53\% selectivity on curcumin, hence the lowest one.

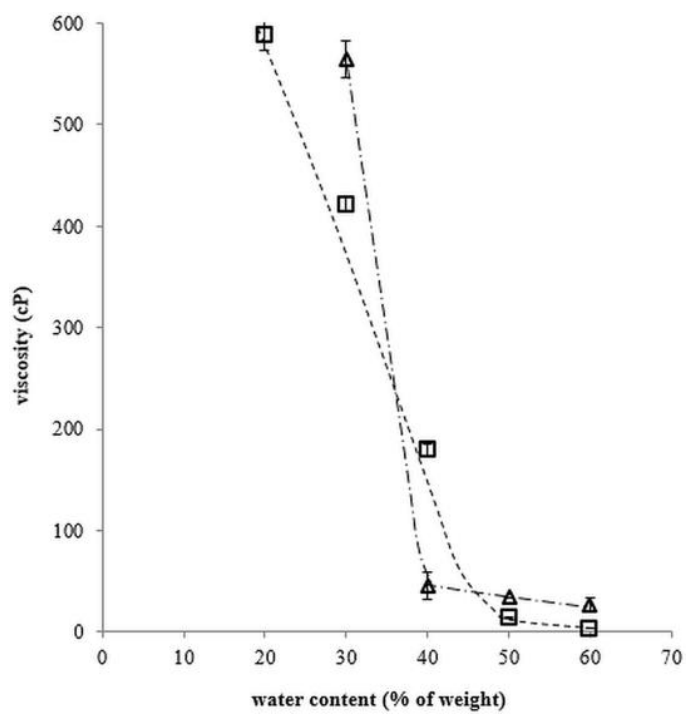

Fig. 1. Relationship between viscosity and percentage of water content of CAS- $\mathrm{H}_{2} \mathrm{O}(\square)$ and $\mathrm{MAS}-\mathrm{H}_{2} \mathrm{O}(\triangle)$.

\subsection{Physical properties of NADES}

Inherent high viscosity of NADES making a limitation especially to the extraction application, hamper mass transfer of target compound form plant matrix to the bulk of solvent, i.e. NADES. Hence, mass transfer resistance is increased.

Viscosity is the major obstacle for the application of NADES. Therefore, a mole ratio of water both at CAS$\mathrm{H}_{2} \mathrm{O}$ and MAS- $\mathrm{H}_{2} \mathrm{O}$ are varied. Consequently, physical properties of NADES, e.g. viscosity, density, solubilizing capacity, were altered, leading in some cases a higher solubility of rutin, carthamin, and cinnamic acid [11]. The viscosity and density of NADES were shown at Fig. 1 and Fig. 2, respectively.

Dilution of NADES by adding water was dramatically lowering the viscosity (Fig. 1), especially when the water content was $>40 \%$. The viscosity of NADES is affected by percentage of water and temperature as well as the density. The density of all tested NADES proved to be higher than that of water (Fig. 2). The higher the water percentage, decreasing the density. Lastly, closer to the water density.

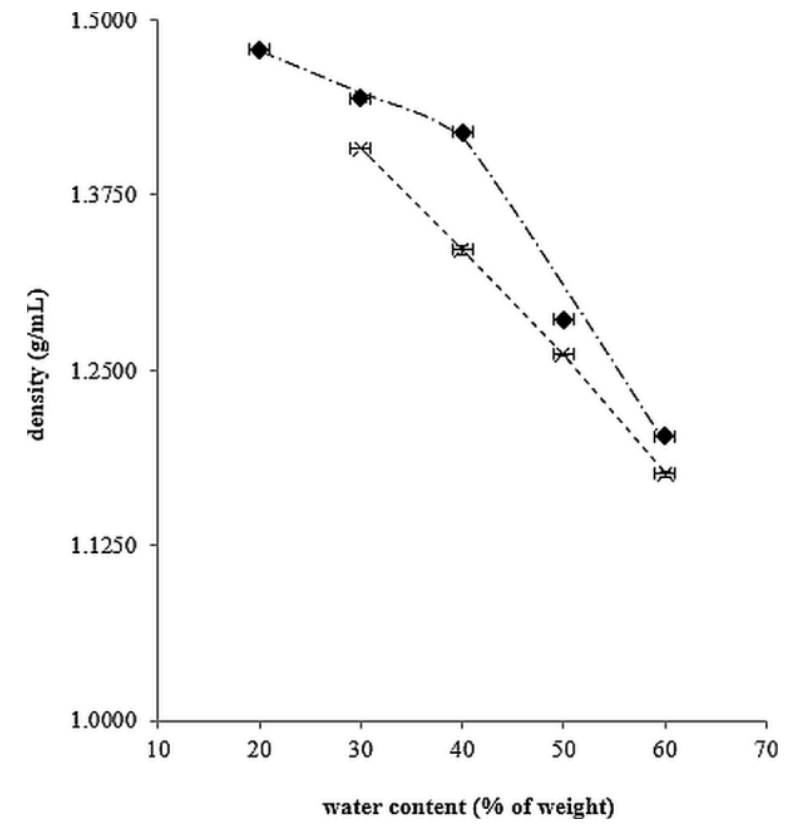

Fig. 2. Relationship between density and percentage of water content of CAS- $\mathrm{H}_{2} \mathrm{O}(\diamond)$ and MAS- $\mathrm{H}_{2} \mathrm{O}(\times)$.

\subsection{Solubilizing ability of NADES}

The influence of water content on the solubilizing capacity of both CAS- $\mathrm{H}_{2} \mathrm{O} \quad(1: 2: 15,20 \%$ of water content) and MAS- $\mathrm{H}_{2} \mathrm{O}$ (1:1:11, 30\% of water content) was investigated (Fig. 3). Water content of both NADES was variated by adding a specified amount of water, reaching the required percentage of water content.

Dilution of NADES decreasing its solubilizing capacity to curcuminoids. Which is reasonable, considering that curcumin has very low solubility in water at $\mathrm{pH}=1-7[4,5]$. Either $\mathrm{CAS}-\mathrm{H}_{2} \mathrm{O}$ or $\mathrm{MAS}-\mathrm{H}_{2} \mathrm{O}$ are an acid solution, $\mathrm{pH}=2$, measured after $10 \mathrm{x}$ diluted with aquadest. However, its native $\mathrm{pH}$ cannot be 
determined due to the viscous property of NADES. This results show that water is an important factor in optimizing NADES.

However, when the percentage of water reached $60 \%$, the obtained yield is comparable to $30 \%$ of water. Though, extensive dilution of NADES resulting in the loss of existing hydrogen bonds, consequently the disappearance of superstructure of NADES [11]. In case of CAS $-\mathrm{H}_{2} \mathrm{O}$ or $\mathrm{MAS}-\mathrm{H}_{2} \mathrm{O}$, the $60 \%$ of water content yielded a similar amount of curcuminoids compared to $20-30 \%$ of water content. Concluded, both viscosity and density of NADES do not influenced the obtained yield.

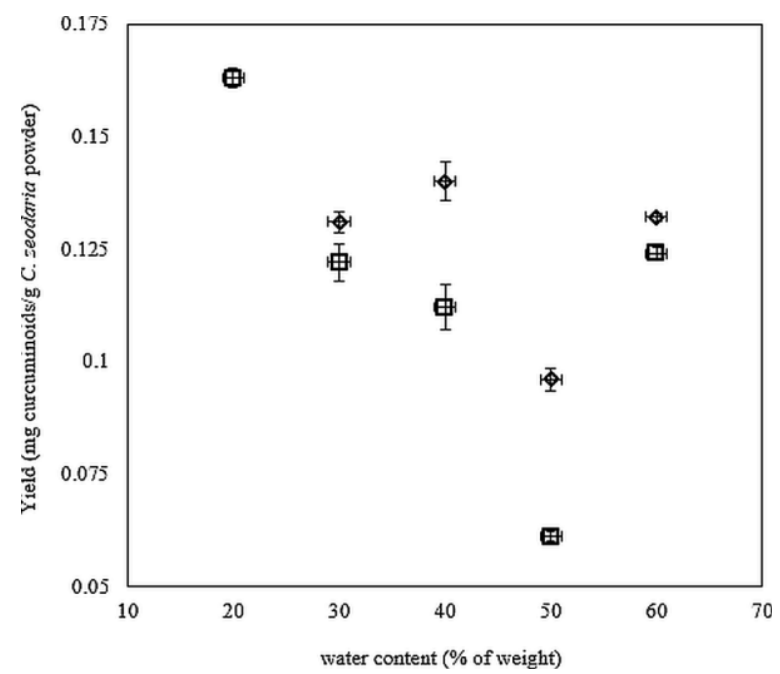

Fig. 3. Extractability of curcuminoids in acidic type of NADES diluted with different percentage of water content $\left(\mathrm{CAS}-\mathrm{H}_{2} \mathrm{O}\right.$ $(\square)$ and MAS- $\left.\mathrm{H}_{2} \mathrm{O}(\triangle)\right)$.

Exploring whatever yield increase or decrease, the extraction time was prolonged to $96 \mathrm{~h}$ (4 days). A prolonged extraction was conducted using CAS- $\mathrm{H}_{2} \mathrm{O}$ ( $20 \%$ of water) and MAS- $\mathrm{H}_{2} \mathrm{O}$ ( $40 \%$ of water) since both of them gave the highest yield of curcuminoids (Fig. 3).

Remarkably, $96 \mathrm{~h}$ of extraction time of curcuminoids with $\mathrm{CAS}-\mathrm{H}_{2} \mathrm{O}$ yielded fourth times higher than $24 \mathrm{~h}$ extraction, ca. $0.676 \mathrm{mg}$ curcuminoids/g dry weight. Whereas MAS- $\mathrm{H}_{2} \mathrm{O}$ yielded lower value of curcuminoids, ca. $0.083 \mathrm{mg}$ curcuminoids/g dry weight; $50 \%$ lower than $24 \mathrm{~h}$ of extraction time. Hence, curcuminoids more stable in $\mathrm{CAS}-\mathrm{H}_{2} \mathrm{O}$ than $\mathrm{MAS}-\mathrm{H}_{2} \mathrm{O}$.<smiles>O=C(O)CC(O)(CC(=O)O)C(=O)O</smiles><smiles>O=C(O)CC(O)C(=O)O</smiles>

Fig. 4. Chemical structure of citric acid (a) and malic acid (b).

Considering the structure between citric acid and malic acid (Fig. 4), the presence of extra hydroxyl or carboxyl groups allowing more hydrogen bond to be formed. Hence increasing the stability of NADES. In case of organic acid with more carboxylic groups, such as citric acid, can form stable liquids than those with less carboxylic groups as in the case of malic acid. The more hydrogen bond are formed, more curcuminoids will be extracted.

Acknowledgement. Sari Herbal (Sukun, Malang, Indonesia) is acknowledged for supplying fine powder of C. zeodaria. OR is grateful for a grant No. 695/PKS/ITS/2017 from Lembaga Penelitian dan Pengabdian Masyarakat (LPPM) of Institut Teknologi Sepuluh Nopember, Surabaya, Indonesia, Kementrian Riset, Teknologi dan Pendidikan Tinggi.

\section{Conclusions}

Water content of NADES significantly influence the physical properties of NADES, i.e. density and viscosity, subsequently also the polarity and extracting capability. In case of acidic type of NADES, i.e. CAS- $\mathrm{H}_{2} \mathrm{O}$ and MAS- $\mathrm{H}_{2} \mathrm{O}$, with various water content; all the variated NADES were successfully extracted curcuminoids from Curcuma zeodaria powder. Yielded 0.06-0.16 mg curcuminoids/g dry weight. However, $60 \%$ of water content of both CAS- $\mathrm{H}_{2} \mathrm{O}$ and $\mathrm{MAS}-\mathrm{H}_{2} \mathrm{O}$ gave more or less similar value of curcuminoids to CAS- $\mathrm{H}_{2} \mathrm{O}(20 \%$ of water) and $\mathrm{MAS}-\mathrm{H}_{2} \mathrm{O}$ (30\% of water). Curcuminoids is more stable in $\mathrm{CAS}-\mathrm{H}_{2} \mathrm{O}$ compare to $\mathrm{MAS}-\mathrm{H}_{2} \mathrm{O}$ when it was extracted for prolonged time, ca. $96 \mathrm{~h}$.

\section{References}

1. G. K. Jayaprakasha, L. Jagan Mohan Rao, and K. K. Sakariah, J. Agric. Food Chem., 50, 3668, (2002).

2. G. Bar-Sela, R. Epelbaum, and M. Schaffer, Curr. Med. Chem., 17, 190, (2010).

3. P. Anand, A. B. Kunnumakkara, R. A. Newman, and B. B. Aggarwal, Molec. Pharm., 4, 807, (2007).

4. M. Salem, S. Rohani, and E. R. Gillies, RSC Adv., 4, 10815, (2014).

5. H. H. Tønnesen and J. Karlsen, Z. Lebens. Unters. Forsch., 180, 402, (1985).

6. G. Shoba, D. Joy, T. Joseph, M. Majeed, R. Rajendran, and P. S. S. R. Srinivas, Planta Med, 64, 353, (1998).

7. M. Cruz-Correa, D. A. Shoskes, P. Sanchez, R. Zhao, L. M. Hylind, S. D. Wexner, et al., Clinic. Gastro. Hepatol., 4, 1035,

8. S. P. Verma, E. Salamone, and B. Goldin, Biochem. Biophys. Res. Comm., 233, 692, (1997).

9. Y. H. Choi, J. van Spronsen, Y. Dai, M. Verberne, F. Hollmann, I. W. C. E. Arends, G. J. Wiktamp, R. Verpoorte, Plant Physiol., 156, 1701, (2011).

10. S. Zullaikah, O. Rachmaniah, A. T. Utomo, H. Niawati, and Y.-H. Ju, "Green Separation of Bioactive Natural Products using Liquefied Mixture of Solids," in Green Chemistry. InTechOpen, 2017, (accepted).

11. Y. Dai, J. van Spronsen, G. J. Witkamp, R. Verpoorte, and Y. H. Choi, Anal. Chim. Acta, 766, 61, (2013).

12.A. K. Popuri and B. Pagala, Int. J. Innov. Res. Studies, 2, 289, (2013). 